\title{
Parent-Child Interaction Therapy: A Comparison of Standard and Abbreviated Treatments for Oppositional Defiant Preschoolers
}

\author{
Reginald D. V. Nixon, Lynne Sweeney, Deborah B. Erickson, and Stephen W. Touyz \\ University of Sydney
}

\begin{abstract}
Families of 54 behaviorally disturbed preschool-aged children ( 3 to 5 years) were randomly assigned to 1 of 3 treatment conditions: standard parent-child interaction therapy (PCIT; STD); modified PCIT that used didactic videotapes, telephone consultations, and face-to-face sessions to abbreviate treatment; and a no-treatment waitlist control group (WL). Twenty-one nondisturbed preschoolers were recruited as a social validation comparison condition. Posttreatment assessment indicated significant differences in parent-reported externalizing behavior in children, and parental stress and discipline practices from both treatment groups on most measures compared with the WL group. Clinical significance testing suggested a superior effect for the STD immediately after intervention, but by 6-month follow-up, the two groups were comparable. The findings indicate that abbreviated PCIT may be of benefit for families with young conduct problem children.
\end{abstract}

The majority of intervention studies for children with conduct problems have focused on children ages 7 or older, when it is likely that the problems have become increasingly entrenched, especially by late adolescence (e.g., Coie \& Koeppl, 1990; Dumas, 1989; Kazdin, 1987a, 1987b; Reid, 1993; Webster-Stratton, 1991, 1993). A number of outcome studies, however, have included preschool-aged children (see Eyberg, 1992; Lavigne \& Reisinger, 1984; Webster-Stratton, 1993, for reviews). Parent management training (PMT) and parent-child interaction therapy (PCIT) have been the most commonly evaluated and promising treatment modalities for externalizing problems in children (Foote, Eyberg, \& Schuhmann, 1998; Kazdin \& Weisz, 1998; Miller, 1994). PCIT (Eyberg, 1988) focuses on improving child-parent relationships and providing parents with skills to manage disruptive behavior. Evaluations of PCIT in individual (Brestan, Eyberg, Boggs, \& Algina, 1997; Eisenstadt, Eyberg, McNeil, Newcomb, \& Funderburk, 1993; McNeil, Capage, Bahl, \& Blanc, 1999; McNeil, Eyberg, Eisenstadt, Newcomb, \& Funderburk, 1991; Schuhmann, Foote, Eyberg, Boggs, \& Algina, 1998) and group format (Auerbach, Nixon, Forrest, Gooley, \& Gemke, 1999) have indicated that it reduces deviant child behavior and promotes positive parentchild relationships. The available evidence suggests that the preschool years are a critical window for early intervention for conduct problems (McMahon, 1994).

Reginald D. V. Nixon, Lynne Sweeney, Deborah B. Erickson, and Stephen W. Touyz, Department of Psychology, University of Sydney, Sydney, Australia.

This research was conducted as part of Reginald D. V. Nixon's doctoral dissertation, sections of which were presented at the First Annual ParentChild Interaction Therapy Conference, May 2000, Sacramento, California. We thank all the families who participated in the study and the following people who assisted with the research: Margaret Charles, Rose Cumberland, Marita Brack, and Gerri Minshall.

Correspondence concerning this article should be addressed to Reginald D. V. Nixon, who is now at the School of Psychology, Flinders University, GPO Box 2100, Adelaide, South Australia 5001 Australia. E-mail: reg.nixon@ flinders.edu.au
Although treatment outcome studies of families with behaviorally disturbed children have shown that PMT and PCIT are effective in reducing antisocial or externalizing behavior in children, individually administered programs that rely on live modeling and feedback have been criticized as costly and inefficient (WebsterStratton, 1984). Thus, a recent focus of interventions for children's behavior problems has been to examine methods of making such programs more accessible for families to attend, as well as on aiding the clinician's ability to administer them. For example, although Webster-Stratton and Hammond (1997) found that treatment for families with early conduct-disordered children (ages 4 to 8 years) reduced conduct problem behaviors, the demands on families were onerous, with treatment consisting of weekly sessions for almost 6 months. Considering that most clinic-referred children drop out of treatment after an average of 10 sessions (Weisz, Thurber, Sweeney, Proffitt, \& LeGagnoux, 1997), and that the perception that treatment is excessively demanding interferes with therapeutic change (Kazdin \& Wassell, 1999), the need for brief interventions is paramount.

To this end, recent modifications to standard delivery practices have included the use of the telephone, self-instructional manuals, and videotape modeling (see Connell, Sanders, \& Markie-Dadds, 1997; Sutton, 1992; Webster-Stratton, Kolpacoff, \& Hollinsworth, 1988). Such alternative delivery methods, however, have not been examined with PCIT. In addition, previous outcome studies of PCIT have had limitations. First, treatment outcome findings for PCIT have yet to be replicated by an independent research unit. Second, previous studies have failed to index subjective reports of parental feelings of competence and enjoyment of parenting (Nixon, Sweeney, \& Touyz, 1999). Third, although a major goal of PCIT is to modify maladaptive or ineffectual parenting techniques, few outcome studies with preschoolers have assessed this. Finally, existing PCIT studies rarely report independent treatment fidelity assessment to verify the content of intervention (Schuhmann et al., 1998, being an exception). The quality of treatment, however, has not been assessed. 
The current study reports the findings from a treatment outcome study for oppositional preschoolers and their parents. Families were randomly allocated to one of three groups: (a) standard PCIT (STD), (b) an abbreviated format of PCIT (ABB) that used instructional videotapes and telephone consultations during therapy, and (c) a no-treatment waitlist control group (WL). In addition, a group of nonproblem preschoolers and their families was recruited as a social validation comparison group (SV) to supplement tests of clinical significance. Extensive assessment was carried out at pretreatment, posttreatment, and 6-month follow-up.

The study had a number of aims. First, we investigated whether abbreviation of the standard format of PCIT diluted its effectiveness in reducing conduct-problem behavior in young children. Second, we attempted to independently replicate previous findings of PCIT outcomes. Third, we intended to carefully evaluate treatment outcome of conduct-problem children and their families by measuring improvement not only in deviant child behavior but also in parental behaviors, beliefs and discipline practices. We hypothesized that: (a) parental behaviors and disciplinary methods in the STD and ABB treatments would be comparable and that they would become more positive and appropriate, and (b) these changes would be superior to those exhibited in the WL group. We also hypothesized that children and parents in the STD and ABB group would not be differentiated from nonproblem families (SV) after intervention.

\section{Method}

\section{Participants}

Local child and family mental health teams, early childhood centers, preschools, and newspapers were notified of a free treatment program for families who had preschool-aged children exhibiting behavioral difficulties. SV families were recruited by advertising in local papers. Ninety-two families of children aged between 3 and 5 years self-referred to participate in the study (71 clinic families, $21 \mathrm{SV}$ families). Inclusion and exclusion criteria were met through a telephone screen and assessment interview. Inclusion criteria for clinic families were (a) the child was in the clinical range on the Eyberg Child Behavior Inventory (ECBI; Eyberg \& Pincus, 1999; Intensity score $\geq 132$ ); (b) the child met diagnostic criteria for oppositional defiant disorder (ODD) according to the fourth edition of the Diagnostic and Statistical Manual of Mental Disorders (DSM-IV; American Psychiatric Association, 1994); and (c) the primary referral problem was disruptive behavior that had been present for at least 6 months. Exclusion criteria were behavior problems because of organic pathology, trauma, or history of severe physical or mental deficits and receiving medication to manage behavioral difficulties. Children were accepted into the SV group if their parents reported that they were not experiencing difficulties in managing their child's behavior, the children's scores on the ECBI were in the normal range, and they did not meet $D S M-I V$ criteria for ODD.

The final clinic group consisted of 38 boys and 16 girls whose mean age was 46.75 months $(S D=6.63)$. For the STD group, 17 families ( 14 boys, 3 girls) completed treatment, and 5 families (23\%) dropped out. Mothers and fathers were a mean age of $34.65(S D=4.72)$ and $37.35(S D=5.92)$ years, respectively. There were 20 completers (13 boys, 7 girls) and 3 dropouts (13\% drop-out rate) in the ABB treatment, and of the 18 families in the WL condition, 1 family did not return for the second assessment (11 boys, 6 girls). Mothers and fathers in the ABB group had a mean age of $33.45(S D=5.28)$ and $35.70(S D=5.96)$ years, respectively, and in the WL group, $34.18(S D=5.76)$ and $37.41(S D=7.45)$ years, respectively. Across the three clinical groups, mothers and fathers had 6 years or less of high school education and had an annual family income in the (U.S.) $\$ 23,200-\$ 40,599$ range. Three families were excluded after initial assessment ( 2 children had significant developmental delays, and 1 child had a history of physical abuse). Additionally, four ABB families attended the initial assessment but did not begin treatment. There were 4 single parents in the STD group, 3 in the ABB group, and 2 in the WL group. Five fathers in the STD group attended between one and four sessions, and 7 fathers in the $\mathrm{ABB}$ group attended between one and five sessions. One father in the ABB condition attended all sessions. Completers and noncompleters did not differ on any demographic or pretreatment variables. The SV group was composed of 15 boys and 6 girls with a mean age of 44.71 months $(S D=5.82)$, with 19 children coming from partnered families. The mothers were a mean age of $35.52(S D=5.00)$ years and fathers were a mean of 38.05 ( $S D=5.79)$ years. In terms of education, SV mothers and fathers had, on average, completed some technical/trade college, and their average income fell in the (U.S.) \$23,200-\$40,599 range. All families spoke English at home and considered themselves Australian for demographic purposes. All families in the STD group were Caucasian, and 1 family in each of the ABB, WL, and SV groups was Australian Koori, Australian Chinese, and Australian Indian, respectively. The four groups were equivalent on all demographic variables except for maternal education, with clinic mothers being less educated than SV mothers, $t(71)=$ $-2.57, p<.01$

\section{Procedure}

Families interested in participating were initially screened by phone, then child and parent(s) attended a 2-hr assessment session. Reginald D. V. Nixon interviewed parents to determine the diagnostic status of their child, parents completed questionnaires, and we conducted a play observation of mother-child interaction, all of which are detailed in the following section.

\section{Measures}

The DSM-IV Structured Interview for Disruptive Behavior Disorders, a modification of a structured interview developed by Campbell, Ewing, Breaux, and Szumowski (1986), was used to determine the presence of ODD according to the criteria outlined by $D S M-I V .{ }^{1}$ Previous research with young conduct problem children has supported this diagnostic method (e.g., Campbell et al., 1986; Lavigne et al., 1994; Schuhmann et al., 1998), and it has been accompanied by good interrater agreement (99\%-100\%; Eisenstadt et al., 1993; McNeil et al., 1991). To index the severity of behavior, a scorer rated each symptom on a 4 -point scale $(1=$ rarely, $4=$ very often) and summed them to give a total score for each diagnostic category.

\section{Parent Report of Child Behavior}

Mothers' perceptions of children's behavior were measured using the following established instruments: the ECBI, the Child Behavior Checklis (CBCL; Achenbach \& Rescorla, 2000), ${ }^{2}$ and the Home Situations Questionnaire-Modified (HSQ-M; Matthey \& Barnett, 1999). For the ECBI, the 36-item Intensity score was used, and fathers were also asked to

\footnotetext{
${ }^{1}$ Unless otherwise specified, all measures are based on maternal report. Data were collected for fathers in partnered families using the ECBI

${ }^{2}$ In consultation with the authors of the $\mathrm{CBCL}$, it was recommended that a new revised version of the 99-item CBCL/2-3 (Achenbach, 1992) be used that was suitable for children between the ages of 1.5 and 5 (T. M. Achenbach, personal communication, December 3, 1997). Because standardized scoring was unavailable at the time of writing, raw scores are reported as recommended by the authors (T. M. Achenbach, personal communication, December 15, 1999).
} 
complete this measure. The Externalizing subscale of the CBCL was used. The HSQ-M is a modified version of Barkley and Edelbrock's (1987) Home Situations Questionnaire (HSQ). This 24-item version by Matthey and Barnett (1999) includes an additional 8 items and assesses difficult behavior over a number of settings. It has good test-retest reliability ( $r=$ $.97)$, acceptable internal consistency $(r=.56-.67)$, and it is correlated with the CBCL $(p<.05)$. The Severity subscale was used in this study.

\section{Parenting Attitudes and Discipline Methods}

Parenting Stress Index (PSI; Abidin, 1995). The Child Domain of the PSI contains 50 items and was used to measure stress associated with difficult qualities or characteristics of children that can lead to frustration and unfulfillment in the parenting role. Abidin (1995) comprehensively reported reliability and validity data of the measure.

Parent Sense of Competence Scale (PSOC; Gibaud-Wallston \& Wandersman, 1978). This 16-item questionnaire was designed as a measure of parenting self-esteem and measures two aspects of parents' self-reported competence: their feelings of satisfaction and efficacy in the parenting role. The total score was used in the current study. Johnston and Mash (1989) reported satisfactory test-retest reliability (ranging between .46 and .82 ) and a significant inverse relationship between the scale and the CBCL.

Parent Locus of Control Scale (PLOC; Campis, Lyman, \& PrenticeDunn, 1986). The PLOC is a 47 -item measure with five subscales, the summation of which gives a total score indicating the degree to which parents feel that they can influence or control their child's behavior. The total score has adequate internal consistency $(\alpha=.92)$ and concurrent validity (Lefcourt, 1991) and discriminates between parents who report management problems with their children and those who do not (Campis et al., 1986).

Parenting Scale (PS; Arnold, O'Leary, Wolff, \& Acker, 1993). Assessment of parenting styles was carried out using the PS, a 30-item self-report scale designed to measure dysfunctional discipline practices in parents of young children. The measure consists of three subscales: Laxness, Overreactivity and Verbosity. The Overreactivity subscale was used in the present study and assesses harsh, aggressive, and authoritarian discipline behaviors. Internal consistency and test-retest reliability (over 2 weeks) are both .82; the scale has been validated against independent observations of parents' disciplinary behavior (Arnold et al., 1993) and discriminates between clinic and nonclinic mothers and fathers (Arnold, O'Leary, \& Edwards, 1997; Smith \& O'Leary, 1995).

\section{Independent Assessment of Child and Parent Behavior}

Using the Dyadic Parent-Interaction Coding Systems-II (DPICS-II; Eyberg, Bessmer, Newcomb, Edwards, \& Robinson, 1994), we conducted observations of parent-child interactions in the clinic. These were coded using an observational measure designed for the assessment of parentchild social interactions in three 5-min standardized situations during which the level of control a parent had in the interaction was manipulated (Eyberg, Boggs, \& Algina, 1995). There were five variables of interest over the 15-min assessment: Total number of parental praises, total number of parental criticisms, total number of parental commands, total child compliance (reported as a percentage), and total child deviant behavior (sum of children's criticisms, smart talking, whining, yelling, destructive behaviors, and physical negatives).

All interactions were videotaped, then randomized and coded by an undergraduate research assistant who was unaware of the aims of the study, group allocation, and time of assessment. The research assistant received $40 \mathrm{hr}$ of training with the aid of the coding training manual recommended for DPICS-II (Eyberg, Edwards, Bessmer, \& Litwins, 1994) and had to meet (or exceed) $80 \%$ agreement with Reginald D. V. Nixon on two precoded tapes prior to coding the parent-child interactions. To maintain coding reliability and to guard against coder drift, we held weekly 1-hr meetings to review coding principles and to discuss any difficulties. A proportion of assessment tapes $(10 \%, n=24)$ was randomly selected and recoded by the same research assistant to examine test-retest reliability. The average reliability coefficient was .91 (ranging between .89 for total child deviance and .96 for total number of parental praises), with the intervals between coding ranging between 4 weeks and 4 months $(M=90$ days).

\section{Treatment}

Both treatments (STD and $\mathrm{ABB}$ ) were conducted as set out by the clinicians' guide for PCIT, Parent-Child Interaction Therapy by HembreeKigin and McNeil (1995), with the recommended session components and durations closely followed. PCIT has two major phases. First, there is a focus on improving the child-parent relationship by teaching parents to play with their children in a positive, nondirective manner based on the play therapy of Hanf (1969) and labeled special playtime (Sessions 1 to 5). During this phase, parents are also taught basic skills (e.g., selective ignoring, labeled praise) to help modify unwanted behaviors of their child that would respond to such strategies. The focus of the second phase (labeled discipline skills, Sessions 6 to 12) was to teach parents skills and strategies in behavior management, using clear instructions in terms of commands to children and appropriate consequences for noncompliance (e.g., time-out and withdrawal of privileges). The STD treatment consisted of twelve $1-2 \mathrm{hr}$ weekly sessions (depending on session content). ${ }^{3}$ For the $\mathrm{ABB}$ treatment, rather than conducting a face-to-face training session to teach parents the skills of the two treatment phases, Reginald D. V. Nixon discussed and modeled these skills on videotape and gave a copy to the family to watch at home. Five face-to-face sessions were alternated with five 30-min telephone consultations to deliver intervention to the $A B B$ group. Both the STD and ABB treatment included a 1-hr booster session (face-to-face) 1-month posttreatment. This booster consisted of checking progress, discussing remaining or new problem behaviors and strategies to handle such problems, and reviewing the rationale and skills of treatment components. Formal coding of parent-child interactions or quantitative assessment was not carried out in the booster session, but coaching of skills was conducted during the treatment component review. The STD treatment took $15.5 \mathrm{hr}$ to administer, the ABB treatment, $9.5 \mathrm{hr}$.

\section{Treatment Integrity and Quality}

Reginald D. V. Nixon, a master's-level clinical psychologist undertaking his clinical doctorate, carried out the treatment. Adherence to treatment protocols and quality of treatment was ensured in the following fashion. First, prior to each session the therapist reviewed the aims, objectives, and skills of each session as set out by Hembree-Kigin and McNeil (1995). Second, the therapist received ongoing supervision from Lynne Sweeney. Third, sessions were videotaped (or recorded on audiocassette for phone sessions), and $20 \%$ ( 80 of the 400 sessions conducted) were randomly selected and checked for treatment adherence by an undergraduate research assistant. The research assistant used detailed protocol sheets that had been reviewed by the author of the PCIT clinicians' guide and were considered an exact itemization of PCIT sessions (C. B. McNeil, personal communication, November 29, 1999). A check of treatment adherence showed that the average therapist accuracy was $99.6 \%$ (range $=71.4 \%-100 \%$ ). All

\footnotetext{
${ }^{3}$ PCIT is usually administered without specific session limits; instead, treatment continues until the parent has mastered all skills and the child is within the normal range on a behavior-rating scale or no longer meets criteria for ODD. Because of logistical considerations, and after consulting Hembree-Kigin and McNeil's (1995) guidelines (p. 12) for the usual number of sessions required for both special playtime and discipline skills, 12 weeks was selected as the treatment duration for the STD condition.
} 
but 3 sessions had 100\% accuracy. A second research assistant checked $36 \%$ of these tapes $(n=29)$. Interrater reliability was high, with an average agreement of $98.9 \%$, and the two raters reached $100 \%$ agreement for all but 2 sessions.

Two experienced clinical psychologists specialized in treating conduct problem families and working in a public treatment unit independent of the clinic where the study was conducted rated the quality/proficiency of $20 \%$ ( $n=80)$ of the therapy sessions. Sessions were rated for therapists' enthusiasm, empathy, and competence, and an overall rating of session quality was made using an 11-point scale (where $0=$ poor, $10=$ excellent). Both rated all components to be of acceptable proficiency and quality, with means ranging between $7.24(S D=0.87)$ and 7.71 $(S D=0.67)$. There was one significant difference between the two raters, with the mean empathy rating of one $(M=7.24)$ being higher than the other, $M=6.56, t(8)=3.02, p<.05$. These checks indicated that there was a high degree of adherence to the treatment protocols and that the quality of treatment was similarly rated favorably.

\section{Results}

\section{Preliminary Analyses}

A series of analyses of variance (ANOVAs) on parent-report and observational data for the three clinical conditions did not reveal any differences on pretreatment variables, which indicated that randomization had produced comparable groups. The clinical groups were significantly different from the SV group in the expected direction on the five measures chosen to examine clinical significance (ECBI, PSI, DPICS-II criticisms, DPICS-II commands, and DPICS-II compliance). Although clinic mothers were significantly less educated than SV mothers, maternal education was not significantly correlated with the latter measures at posttreatment or follow-up.

\section{Immediate Treatment Effects}

A series of three-group analyses of covariance (ANCOVAs) with planned comparisons ( $t$ statistics) were used to examine the effects of intervention for each dependent variable, using pretreatment measures as covariates.

Table 1 summarizes the means and standard deviations for all dependent variables at each assessment, and Table 2 contains $F$ values, $t$ statistics, and effect sizes for immediate treatment effects. Mothers reported significant differences on three of the four measures of child problem behavior in the three-group ANCOVA. Mothers in both the STD and ABB conditions reported less oppositional and conduct problem behavior (ECBI, ODD symptoms) than mothers in the WL condition. Mothers in the STD condition also reported less severe behavior problems around the home (HSQ-M) compared with WL mothers, but ABB mothers did not. Fathers in the ABB condition reported less oppositional behavior (ECBI) at posttreatment compared with WL, but this was not observed in the STD condition. No significant differences were observed on the CBCL. There were no significant differences between the STD and ABB treatment on the above measures.

The three-group ANCOVA revealed significant differences for all parenting measures immediately after treatment. Less parenting stress was reported by ABB mothers (PSI) than WL mothers, but not by mothers in the STD condition. Compared with mothers in the WL condition, both STD and $\mathrm{ABB}$ mothers reported more satisfaction (PSOC), more control (PLOC), and less overreactive discipline techniques (PS) after treatment. There were no signifi- cant differences between the STD and ABB treatments for these four measures.

In terms of independent observation of parent-child interactions, several significant differences were revealed according to the three-group ANCOVA. Mothers in both treatments (STD, $\mathrm{ABB}$ ) praised their children more and gave fewer commands than WL mothers. Mothers in the STD condition also gave fewer criticisms of their children, and their children were more compliant than those of WL mothers. An effect of intervention on child deviance, however, was not observed for either treatment condition. There were no significant differences between the STD and ABB treatments on any of the above measures.

Clinical significance immediately after treatment. Five relevant indices of treatment outcome were considered: mothers' report of conduct problems and parenting stress (ECBI, PSI) and three independent observations of mother-child interactions (maternal commands and criticisms, and child compliance). These measures were selected to ensure that a range of clinically important behaviors were assessed and that evaluation incorporated both self-report and independently assessed variables. Children were classified as having made clinically significant improvement if mothers' report of behavior or stress fell below the published clinical cutoffs for that measure (132 for the ECBI, Eyberg et al., 1995, and 116 for the PSI, Abidin, 1995) and if this change was determined to be reliable as set out by Jacobson and Truax (1991). ${ }^{4,5}$ A 30\% reduction in commands or criticisms and a 30\% increase in child compliance at posttreatment (compared with baseline level) were also used as an index of change for mother behaviors (e.g., McNeil et al., 1991; Webster-Stratton \& Hammond, 1997). First, individual treatment groups were compared with the WL group; next, the two treatments were compared with the SV group on the five variables of interest. Only children who were in the clinical range on the PSI at pretreatment were considered in analyses for this measure. This was 16, 17, and 13 children for the STD, ABB, and WL conditions, respectively. (All children were in the clinical range on the ECBI at pretreatment.) Table 3 displays the frequency and percentage of children who made clinically significant changes between pre- and posttreatment.

Immediately after treatment, more mothers in the STD condition reported reliable and clinically significant changes on oppositional child behavior and parenting stress than WL mothers. Significant change, however, was not observed for the ABB condition on these measures compared with the WL group. Greater proportions of mothers in both the STD and ABB condition reduced their number of commands by $30 \%$ or more than did WL mothers, and we also found a greater proportion of mothers in the STD condition reduced the number of their criticisms compared with WL mothers, but this was not significant for the ABB condition. Only one difference was noted between the two treatments, with greater proportions of mothers in the STD condition significantly reducing their criticisms than $\mathrm{ABB}$ mothers. Changes in child compliance were not clinically significant for either treatment.

\footnotetext{
${ }^{4}$ Jacobson and Truax (1991) defined a reliable change as a change of more than 1.96 SEMs between pretreatment and posttreatment (or followup).

${ }^{5}$ For detailed descriptions of clinical significance testing, see Kendall (1999).
} 
Table 1

Outcome Variables at Pretreatment, Posttreatment, and 6-Month Follow-Up Assessment

\begin{tabular}{|c|c|c|c|c|c|c|c|c|c|c|c|}
\hline \multirow[b]{2}{*}{ Measure } & \multicolumn{3}{|c|}{ STD } & \multicolumn{3}{|c|}{$\mathrm{ABB}$} & \multicolumn{2}{|c|}{ WL } & \multicolumn{3}{|c|}{ SV } \\
\hline & Pre & Post & Follow-up & Pre & Post & Follow-up & Pre & Post & Pre & Post & Follow-up \\
\hline \multicolumn{12}{|l|}{ Parent report } \\
\hline \multicolumn{12}{|l|}{ ECBI } \\
\hline Mother, $M$ & 166.59 & 125.24 & 117.47 & 156.25 & 126.60 & 126.10 & 173.82 & 148.35 & 108.81 & 105.80 & 110.33 \\
\hline$S D$ & 18.93 & 21.67 & 31.69 & 16.80 & 18.39 & 18.03 & 22.72 & 19.05 & 15.34 & 23.96 & 23.10 \\
\hline Father, $M$ & 148.33 & 124.00 & 120.81 & 139.06 & 114.00 & 115.50 & 147.47 & 134.13 & & & \\
\hline$S D$ & 24.54 & 25.11 & 23.74 & 23.17 & 23.31 & 21.28 & 25.97 & 28.03 & & & \\
\hline \multicolumn{12}{|l|}{ ODD Sx } \\
\hline$M$ & 22.82 & 16.24 & 16.18 & 21.15 & 16.05 & 17.35 & 23.12 & 19.63 & & & \\
\hline$S D$ & 3.17 & 3.85 & 4.33 & 3.57 & 3.14 & 4.66 & 3.02 & 4.27 & & & \\
\hline \multicolumn{12}{|l|}{ CBCL } \\
\hline$M$ & 25.82 & 17.59 & 15.24 & 25.20 & 17.65 & 15.90 & 26.24 & 21.53 & & & \\
\hline$S D$ & 5.22 & 6.54 & 7.77 & 7.33 & 6.06 & 7.33 & 6.26 & 7.19 & & & \\
\hline \multicolumn{12}{|l|}{ HSQ-M } \\
\hline$M$ & 5.07 & 3.96 & 3.52 & 5.68 & 4.46 & 4.21 & 5.71 & 5.42 & & & \\
\hline$S D$ & 1.09 & 1.21 & 1.31 & 1.00 & 1.59 & 1.29 & 1.23 & 1.32 & & & \\
\hline \multicolumn{12}{|l|}{ Parent Behavior } \\
\hline \multicolumn{12}{|l|}{ PSI } \\
\hline$M$ & 135.00 & 114.29 & 107.29 & 132.35 & 112.70 & 109.65 & 131.65 & 124.71 & 92.30 & 89.75 & 89.43 \\
\hline$S D$ & 11.80 & 18.00 & 18.55 & 21.35 & 18.37 & 21.51 & 19.08 & 14.25 & 15.05 & 21.50 & 19.73 \\
\hline \multicolumn{12}{|l|}{ PSOC } \\
\hline$M$ & 50.53 & 57.35 & 57.53 & 50.70 & 56.90 & 57.80 & 51.00 & 51.59 & & & \\
\hline$S D$ & 7.62 & 8.31 & 7.84 & 7.66 & 6.55 & 7.02 & 8.62 & 6.59 & & & \\
\hline \multicolumn{12}{|l|}{ PLOC } \\
\hline$M$ & 131.00 & 111.71 & 110.71 & 131.50 & 117.60 & 116.15 & 136.82 & 133.35 & & & \\
\hline$S D$ & 13.26 & 18.63 & 19.29 & 14.58 & 13.42 & 19.35 & 17.38 & 12.27 & & & \\
\hline \multicolumn{12}{|l|}{ PS } \\
\hline$M$ & 3.49 & 2.56 & 2.71 & 3.71 & 2.82 & 2.98 & 4.02 & 3.74 & & & \\
\hline$S D$ & 0.71 & 0.80 & 0.83 & 0.71 & 0.91 & 1.06 & 0.84 & 0.89 & & & \\
\hline \multicolumn{12}{|c|}{ Independent observations } \\
\hline \multicolumn{12}{|c|}{ Criticisms $^{\mathrm{a}}$} \\
\hline$M$ & 7.06 & 1.71 & 2.56 & 6.37 & 3.39 & 2.84 & 7.35 & 6.13 & 3.05 & 4.28 & 4.16 \\
\hline$S D$ & 6.39 & 2.14 & 3.79 & 5.80 & 2.99 & 2.79 & 8.04 & 6.00 & 3.30 & 2.02 & 3.75 \\
\hline \multicolumn{12}{|l|}{ Praises $^{\mathrm{a}}$} \\
\hline$M$ & 8.53 & 29.59 & 23.62 & 10.25 & 28.42 & 23.79 & 6.53 & 9.88 & & & \\
\hline$S D$ & 6.58 & 12.97 & 13.26 & 11.84 & 17.81 & 14.38 & 5.48 & 8.54 & & & \\
\hline \multicolumn{12}{|l|}{ Commands $^{\mathrm{a}}$} \\
\hline$M$ & 42.53 & 23.77 & 22.94 & 44.75 & 26.68 & 22.00 & 38.41 & 36.94 & 28.30 & 27.89 & 24.63 \\
\hline$S D$ & 21.25 & 9.06 & 9.87 & 23.06 & 12.98 & 8.29 & 23.21 & 14.70 & 11.50 & 12.18 & 11.63 \\
\hline \multicolumn{12}{|c|}{ Child compliance ${ }^{\mathrm{b}}$} \\
\hline$M$ & 0.64 & 0.81 & 0.83 & 0.54 & 0.67 & 0.77 & 0.47 & 0.60 & 0.68 & 0.80 & 0.75 \\
\hline$S D$ & 0.24 & 0.22 & 0.21 & 0.25 & 0.24 & 0.23 & 0.25 & 0.22 & 0.20 & 0.13 & 0.19 \\
\hline Child deviance ${ }^{\mathrm{c}}$ & & & & & & & & & & & \\
\hline$M$ & 12.47 & 5.00 & 5.75 & 9.90 & 6.90 & 7.26 & 14.82 & 7.56 & & & \\
\hline$S D$ & 22.66 & 3.59 & 8.71 & 13.06 & 9.66 & 9.26 & 11.51 & 7.64 & & & \\
\hline
\end{tabular}

Note. $\quad \mathrm{STD}=$ standard treatment $(n=17) ; \mathrm{ABB}=$ abbreviated treatment $(n=20) ; \mathrm{WL}=$ waitlist control $(n=17) ; \mathrm{SV}=\operatorname{social}$ validation group $(n=$ 21). Pre $=$ pretreatment, Post $=$ posttreatment; Follow-up $=6$-month follow-up; 6-month data not applicable for WL; ECBI $=$ Eyberg Child Behavior Inventory (Intensity score); ODD Sx = Intensity of oppositional defiant disorder symptoms from Structured DSM-IV Interview; CBCL = Child Behavior Checklist (Externalizing raw score); HSQ-M = Home Situations Questionnaire: Modified (Severity of problems score); PSI = Parenting Stress Index (Child Domain score); PSOC = Parent Sense of Competence Scale; PLOC = Parent Locus of Control Scale; PS = Parenting Scale (Overreactivity score).

${ }^{a}$ Total number during Dyadic Parent-Interaction Coding System-II (DPICS-II). ${ }^{\mathrm{b}}$ Child compliance during DPICS-II (percentage of commands obeyed). $\quad{ }^{\mathrm{c}}$ Child deviance during DPICS-II (total number of deviant acts).

When comparisons were made with the SV group, mothers from the STD and ABB groups continued to report behavior (ECBI) at a level significantly higher than that of SV mothers, $t(35)=2.57$, $p<.05$, and $t(38)=3.08, p<.01$, respectively. The same findings were observed for parental stress (PSI); for the STD condition, $t(35)=3.73, p<.01$, for the ABB condition, $t(38)=3.63, p<.01$. The number of commands given by STD and $\mathrm{ABB}$ mothers, however, was not significantly different from
SV mothers, and surprisingly, mothers in the STD condition criticized their children significantly less than SV mothers, $t(33)=$ $-3.65, p<.01$. Children in the STD and ABB groups were not significantly different from SV children in terms of their compliance.

Equivalency testing immediately after treatment. We adopted the approach of Rogers, Howard, and Vessey (1993) to test the similarity of the two treatments. In such testing, a predetermined 
Table 2

$F$ Values, $t$ Statistics, and Effect Sizes for Immediate Treatment Effects

\begin{tabular}{|c|c|c|c|c|c|c|c|c|c|c|c|}
\hline \multirow[b]{2}{*}{ Measure } & \multirow{2}{*}{$\begin{array}{c}\text { Three-group } \\
\text { ANCOVA } \\
F\end{array}$} & \multirow[b]{2}{*}{$d f$} & \multicolumn{3}{|c|}{ STD vs. WL } & \multicolumn{3}{|c|}{ ABB vs. WL } & \multicolumn{3}{|c|}{ STD vs. ABB } \\
\hline & & & $t$ & $d f$ & $d$ & $t$ & $d f$ & $d$ & $t$ & $d f$ & $d$ \\
\hline \multicolumn{12}{|l|}{ Parent report } \\
\hline \multicolumn{12}{|l|}{ ECBI } \\
\hline Mother & $5.62 * *$ & 2,50 & $-3.30 * *$ & 32 & 1.13 & $-3.53 * * *$ & 35 & 1.16 & -0.21 & 35 & 0.07 \\
\hline Father & 2.14 & 2,41 & -1.25 & 30 & 0.44 & $-2.14^{*}$ & 28 & 0.78 & 0.97 & 30 & -0.34 \\
\hline ODD Sx & $4.36^{*}$ & 2,50 & $-2.40^{*}$ & 31 & 0.83 & $-2.90 * *$ & 34 & 0.97 & 0.16 & 35 & 0.05 \\
\hline CBCL & 2.22 & 2,50 & -1.67 & 32 & 0.57 & -1.78 & 35 & 0.59 & -0.03 & 35 & 0.01 \\
\hline HSQ-M & $3.76^{*}$ & 2,50 & $-3.36 * *$ & 32 & 1.15 & -1.97 & 35 & 0.65 & -1.06 & 35 & 0.35 \\
\hline \multicolumn{12}{|l|}{ Parent behavior } \\
\hline PSI & $3.96^{*}$ & 2,50 & -1.87 & 32 & 0.64 & $-2.19^{*}$ & 35 & 0.72 & 0.27 & 35 & -0.09 \\
\hline PSOC & $5.64 * *$ & 2,50 & $2.24 *$ & 32 & 0.77 & $2.45^{*}$ & 35 & 0.81 & 0.19 & 35 & -0.06 \\
\hline PLOC & $10.09 * * *$ & 2,50 & $-4.00 * * *$ & 32 & 1.37 & $-3.70 * *$ & 35 & 1.22 & -1.12 & 35 & 0.37 \\
\hline PS & $6.14 * *$ & 2,50 & $-4.08 * * *$ & 32 & 1.40 & $-3.08 * *$ & 35 & 1.02 & -0.92 & 35 & 0.30 \\
\hline \multicolumn{12}{|c|}{ Independent observations } \\
\hline Criticisms $^{\text {a }}$ & $6.14 * *$ & 2,48 & $-2.94 * *$ & 31 & 1.02 & -1.91 & 33 & 0.65 & -1.72 & 34 & 0.57 \\
\hline Praises $^{\mathrm{a}}$ & $9.65 * * *$ & 2,48 & $5.12 * * *$ & 31 & 1.78 & $3.81 * * *$ & 33 & 1.29 & 0.22 & 34 & 0.07 \\
\hline Commands ${ }^{\mathrm{a}}$ & $10.38 * * *$ & 2,48 & $-3.12^{* *}$ & 31 & 1.09 & $-2.19 *$ & 33 & 0.74 & -0.77 & 34 & 0.26 \\
\hline Child compliance ${ }^{\mathrm{b}}$ & 2.68 & 2,48 & $2.77 * *$ & 31 & 0.96 & 0.89 & 33 & 0.30 & 1.82 & 34 & 0.61 \\
\hline Child deviance ${ }^{\mathrm{c}}$ & 0.54 & 2,48 & -1.25 & 31 & 0.43 & -0.22 & 33 & 0.08 & -0.76 & 34 & 0.25 \\
\hline
\end{tabular}

Note. $\mathrm{ANCOVA}=$ analysis of covariance; $\mathrm{STD}=$ standard treatment $(n=17)$; $\mathrm{ABB}=$ abbreviated treatment $(n=20)$; WL $=$ waitlist control $(n=$ 17). $\mathrm{ECBI}=$ Eyberg Child Behavior Inventory (Intensity score); ODD Sx = Intensity of oppositional defiant symptoms from Structured $D S M-I V$ Interview; $\mathrm{CBCL}=$ Child Behavior Checklist (Externalizing raw score); HSQ-M = Home Situations Questionnaire: Modified (Severity of problems score); PSI = Parenting Stress Index (Child Domain score); PSOC = Parent Sense of Competence Scale; PLOC = Parent Locus of Control Scale; PS = Parenting Scale (Overreactivity score).

${ }^{a}$ Total number during Dyadic Parent-Interaction Coding System-II (DPICS-II) by mother. ${ }^{\mathrm{b}}$ Child compliance during DPICS-II (percentage of commands obeyed). ${ }^{\mathrm{c}}$ Child deviance during DPICS-II (total number of deviant acts).

$* p<.05 . \quad * * p<.01 . \quad * * * p<.001$.

nonzero difference value (also known as an equivalence interval) is defined as a difference between two treatments that is considered to be clinically unimportant. The researcher then tests the null hypothesis that the difference between the two treatment means on a particular variable is equal to or larger than the specified difference. Equivalency is derived statistically when the null hypothesis is rejected and the alternative hypothesis, that the difference between the two groups is smaller than the predetermined difference, is accepted. For the purpose of examining equivalency, the two treatments were considered comparable if the mean score of the ABB treatment fell within $1 S D$ of the STD group mean. We chose this cutoff because we felt that any difference score that fell within

Table 3

Clinical Significance for Children's Problem Behavior Immediately After Treatment

\begin{tabular}{|c|c|c|c|c|c|c|c|c|c|c|c|c|}
\hline \multirow[b]{2}{*}{ Measure } & \multicolumn{2}{|c|}{ STD } & \multicolumn{2}{|c|}{$\mathrm{ABB}$} & \multicolumn{2}{|c|}{ WL } & \multicolumn{6}{|c|}{ Contrast, $\chi^{2}(1)$} \\
\hline & $n$ & $\%$ & $n$ & $\%$ & $n$ & $\%$ & STD vs. WL & $N$ & ABB vs. WL & $N$ & STD vs. ABB & $N$ \\
\hline \multicolumn{13}{|l|}{$\mathrm{RCI}>1.96$} \\
\hline ECBI & 12 & 71 & 11 & 55 & 9 & 53 & 1.12 & 34 & 0.02 & 37 & 0.95 & 37 \\
\hline PSI & 8 & 50 & 9 & 53 & 2 & 14 & $4.29 *$ & 30 & $5.01 *$ & 31 & 0.03 & 33 \\
\hline \multicolumn{13}{|c|}{ Movement from clinical to normal range } \\
\hline ECBI & 12 & 71 & 8 & 40 & 3 & 18 & $9.66 * *$ & 34 & 2.20 & 37 & 3.46 & 37 \\
\hline PSI & 10 & 63 & 9 & 53 & 2 & 14 & $7.23 * *$ & 30 & $5.01 *$ & 31 & 0.31 & 33 \\
\hline \multicolumn{13}{|l|}{ RCI and clinical movement } \\
\hline ECBI & 10 & 59 & 6 & 30 & 2 & 12 & $8.24 * *$ & 34 & 1.80 & 37 & 3.11 & 37 \\
\hline PSI & 7 & 44 & 6 & 35 & 1 & 8 & $5.12 *$ & 30 & 3.48 & 31 & 0.25 & 33 \\
\hline \multicolumn{13}{|l|}{$30 \%$ change } \\
\hline Commands $\mathrm{a}^{\mathrm{a}}$ & 12 & 71 & 13 & 68 & 4 & 25 & $6.86^{*}$ & 33 & $6.56^{*}$ & 35 & 0.02 & 36 \\
\hline Criticisms $^{\mathrm{a}}$ & 15 & 88 & 11 & 58 & 7 & 44 & $7.34^{*}$ & 33 & 0.70 & 35 & $4.12^{*}$ & 36 \\
\hline Compliance $^{\mathrm{b}}$ & 6 & 35 & 10 & 53 & 5 & 31 & 0.06 & 33 & 1.62 & 35 & 1.09 & 36 \\
\hline
\end{tabular}

Note. $\quad$ STD $=$ standard treatment $\mathrm{ABB}=$ abbreviated treatment $\mathrm{WL}=$ waitlist control; $\mathrm{RCI}=$ reliable change index $; \mathrm{ECBI}=\mathrm{Eyberg}$ Child $\mathrm{Behavior}$ Inventory; PSI = Parenting Stress Index.

${ }^{\mathrm{a}}$ Number by mother during Dyadic Parent-Interaction Coding System-II (DPICS-II). ${ }^{\mathrm{b}}$ Compliance during DPICS-II by child.

$* p<.05$. ** $p<.01$. 
this interval was unlikely to represent an observable clinical difference in our sample. The same indices used to test for clinically significant change were examined to determine equivalency between treatments.

Immediately after treatment, mothers' report of behavior (ECBI) and parenting stress (PSI) was equivalent between the STD and ABB treatments $(z=3.09, p<.001$, and $z=2.73, p<.01$, respectively). Similarly, equivalency was established for independent assessment of the number of commands given by mothers, $z=1.65, p<.05$. Equivalency was not observed between the two treatments, however, for number of maternal criticisms or for child compliance. Rogers et al. (1993) stated that when both traditional and equivalence tests fail (i.e., the null hypothesis is retained for both tests, as in the case on the latter two variables), insufficient evidence exists to make a decision about equivalency.

Additional analyses. We also examined our results more stringently by investigating the consequence of using a Bonferroni correction for the number of tests $(\alpha=.05 / 14)$ and conducting $t$ tests only in the presence of significant ANCOVAs. We adopted this more conservative approach to balance the risk of chance findings (by not controlling for multiple significance tests), while recognizing the need for sensitive analyses to determine whether true effects existed between the STD and ABB treatments. These procedures resulted in seven STD to WL comparisons (mothers' report on ECBI, mothers' report of ODD symptoms, HSQ, PSOC, PS, maternal criticisms, child compliance) and six ABB to WL comparisons (mothers' report on ECBI, fathers' report on ECBI, mothers' report of ODD symptoms, PSI, PSOC, PS) no longer being significant.

\section{Treatment Effects at 6-Month Follow-Up}

Long-term effects were examined through 2 (condition: STD, ABB) $\times 2$ (time: posttreatment, follow-up) repeated measures ANOVAs. Planned contrasts ( $t$ statistics) were used to compare follow-up scores between the treatment conditions. ${ }^{6}$

There were no significant Condition $\times$ Time interactions or main effects for time or condition for any measures. Independent samples $t$ tests revealed no significant differences between the STD and ABB condition at follow-up, and all pre-posttreatment improvements were maintained at follow-up. Effect sizes for STD to $\mathrm{ABB}$ treatment comparisons were as follows: mother ECBI, $d=0.34$; father ECBI, $d=-0.23$; ODD symptoms, $d=0.26$; CBCL, $d=0.09$; HSQ-M, $d=0.53$; PSI, $d=0.12$; PSOC, $d=0.04$; PLOC,$d=0.28$; PS, $d=0.29$; independent observation of mothers' criticisms, $d=0.09$; praises, $d=-0.01$; commands, $d=-0.10$; child compliance, $d=0.26$; child deviance, $d=0.18$.

Clinical significance at follow-up. Table 4 displays the frequency and percentage of children who made clinically significant changes between pretreatment and 6-month follow-up, although there was now no WL condition for comparison purposes. There were no differences between the two treatments in terms of clinically significant reductions in oppositional behavior and parenting stress. Independent assessment of parent behaviors at follow-up indicated that large proportions of mothers in both treatment groups continued to show a $30 \%$ reduction in the number of commands they gave their children compared with their baseline levels. There was also no difference between STD and ABB mothers in terms of a $30 \%$ reduction in criticisms.
Table 4

Clinical Significance for Children's Problem

Behavior at Follow-Up

\begin{tabular}{|c|c|c|c|c|c|}
\hline \multirow[b]{2}{*}{ Measure } & \multicolumn{2}{|c|}{ STD } & \multicolumn{2}{|c|}{$\mathrm{ABB}$} & \multirow{2}{*}{$\begin{array}{l}\text { Contrast }\left(\chi^{2}\right) \\
\text { STD vs. ABB }\end{array}$} \\
\hline & $n$ & $\%$ & $n$ & $\%$ & \\
\hline \multicolumn{6}{|l|}{$\mathrm{RCI}>1.96$} \\
\hline ECBI & 14 & 82 & 15 & 75 & 0.29 \\
\hline PSI & 11 & 69 & 8 & 47 & 0.79 \\
\hline \multicolumn{6}{|c|}{$\begin{array}{l}\text { Movement from clinical to } \\
\text { normal range }\end{array}$} \\
\hline ECBI & 10 & 59 & 14 & 70 & 0.50 \\
\hline PSI & 12 & 75 & 9 & 53 & 0.86 \\
\hline \multicolumn{6}{|c|}{ RCI and clinical movement } \\
\hline ECBI & 10 & 59 & 13 & 65 & 0.15 \\
\hline PSI & 9 & 56 & 4 & 24 & 3.70 \\
\hline \multicolumn{6}{|l|}{$30 \%$ reduction } \\
\hline Commands $^{\mathrm{a}}$ & 12 & 75 & 14 & 74 & 0.01 \\
\hline Criticisms $\mathrm{s}^{\mathrm{a}}$ & 12 & 75 & 11 & 58 & 1.13 \\
\hline Compliance $^{\mathrm{b}}$ & 7 & 44 & 10 & 53 & 0.27 \\
\hline
\end{tabular}

Note. $\mathrm{STD}=$ standard treatment $; \mathrm{ABB}=$ abbreviated treatment $; \mathrm{RCI}=$ reliable change index; ECBI = Eyberg Child Behavior Inventory; PSI = Parenting Stress Index.

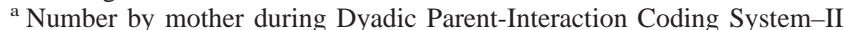
(DPICS-II). ${ }^{\mathrm{b}}$ Compliance during DPICS-II by child.

Compared with the SV condition at follow-up, mothers in the STD and ABB condition did not rate their children as significantly different on the ECBI. Although mean stress levels for both treatments remained in the normal range, they were significantly higher than the level reported by SV mothers, $t(36)=2.85$, for the STD group, and $t(39)=3.14$, for the ABB group $(p<.01$ for both tests). The number of maternal commands given at follow-up was no different between the treated groups and SV group, and this finding was repeated for the number of maternal criticisms and child compliance, with no difference being observed between the treatment groups and SV group. No follow-up findings were affected by more conservative testing (as described under Immediate Treatment Effects).

Equivalency testing at follow-up. Using the procedure described earlier, we examined the comparability of the two treatments at follow-up. These analyses indicated that both treatments were comparable on all measures used previously. That is, mothers' reports of child behavior (ECBI) and parenting stress (PSI) were comparable $(z=2.77, p<.01$, and $z=2.43, p<.01$, respectively), as were independent observations of maternal commands and criticisms $(z=2.99, p<.01$, and $z=3.24, p<.001$, respectively) and child compliance $(z=2.06, p<.05)$.

\section{Discussion}

The present findings suggest that the modified treatment $(\mathrm{ABB})$ and standard PCIT approach (STD) had comparable effects. As well as independently replicating previous findings of the effectiveness of PCIT for families of young children with behavior

\footnotetext{
${ }^{6}$ Although 3-month follow-up data were also collected, these findings were comparable to the 6-month follow-up, thus only the latter is reported All families were available for follow-up.
} 
problems, the current study lends support to the cross-cultural flexibility of PCIT. In addition, the findings indicate that, for the present sample, PCIT could be streamlined without substantially limiting its positive impact on child conduct problems and mothers' self-esteem and confidence in their parenting abilities and remain effective in altering inappropriate discipline behaviors.

There were very few differences statistically between the two treatments immediately after intervention or at 6-month follow-up. At posttreatment, mothers of children in both treatment groups reported significant differences in their children's behavior compared with mothers of WL children. These mothers noted fewer oppositional and conduct problem behaviors, and mothers in the STD condition reported fewer behavior problems around the home. A similar pattern of findings was observed in parenting behaviors after intervention. Compared with WL mothers, ABB mothers reported significantly less stress associated with raising children, and mothers in both treatment conditions reported more satisfaction and competence in their parenting ability, greater feelings of control with regard to their children's behavior, and less use of harsh or overreactive discipline. Independent observations of parent-child interactions in the clinic revealed that mothers in the STD and ABB condition were observed to praise their children more and give fewer commands than WL mothers at posttreatment assessment. STD condition mothers made fewer criticisms, and greater compliance was observed in their children. Fathers in the $\mathrm{ABB}$ condition also reported fewer oppositional behaviors in their children. Although use of more stringent analyses (i.e., Bonferroni corrections) resulted in the elimination of some significant results immediately after treatment, this did not alter the overall pattern of findings of the study. It did, however, remove the independent observation that STD children were more compliant than WL children immediately after treatment. Assessment at 6-month follow-up showed that families of both treatment conditions maintained postintervention gains, and no differences were observed between the STD and $\mathrm{ABB}$ conditions. Using a conservative method of determining clinical significance (RCI and movement from the clinical to nonclinical range), we found superior effects for the STD group immediately after treatment. Thus, clinically significant improvement was observed on four of the five chosen outcome variables for the STD condition, compared with one independent measure for the $\mathrm{ABB}$ condition. By 6-month followup, however, the proportions of $\mathrm{ABB}$ children and parents who had made clinically significant changes had increased and were comparable to the STD condition. Most important, by the 6-month follow-up treatment, families could not be distinguished from the social validation group on four of the five measures used to determine the clinical significance of change (parenting stress being the exception). Equivalency testing also indicated comparability of the treatments at follow-up.

Not all findings immediately after treatment were consistent with hypothesized changes. Immediate improvements of conduct problems were not observed on a widely used measure of child externalizing problems (CBCL). This may be due to the form of the CBCL used, with study of its reliability and validity not yet complete, or else it could reflect that it might not be as sensitive as the ECBI in detecting oppositional-type behaviors. Significant differences in child deviance were not detected following treatment, although methodological reasons may have accounted for this (as discussed later). Also of interest was the reported reduction by parents on the ECBI of the WL group at posttreatment assessment. It was thought that this reduction (which nonetheless remained in the clinical range) might have reflected that many families were in crisis when initially assessed and this may have ameliorated to some degree by posttreatment assessment.

The finding that in the short term an abbreviated treatment for early conduct problems may be comparable to a more intensive and time-consuming standard format has several important implications. First, there are logistical and geographical barriers that prevent some families from attending or accessing treatment. The present research has examined an alternative means of delivering clinical services as recommended by researchers and clinicians in the field (Herschell, Calzada, Eyberg, \& McNeil, 2002; Sanders, 1996) and has found it has the potential to effectively reach families who might otherwise be unable to access mental health services on a regular basis (e.g., rural populations). Second, this finding is extremely relevant to the issue of making interventions more cost-effective (Chambless \& Hollon, 1998). Although parent training methods are effective in treating conduct problems, they are also costly to implement (Patterson, Dishion, \& Chamberlain, 1993). In light of ever decreasing funds for mental health services and the common presence of long waiting lists, there is increasingly a push for services to be time restricted and cost-effective, especially in the environment of managed care. This research is also in line with recommendations that brief interventions for child problems be further studied (Weisz et al., 1997), and it has offered preliminary support that a time- and cost-efficient intervention may result in beneficial therapeutic effects for families with young children displaying early conduct problems.

Several limitations of the study are recognized. Methodologically, the STD treatment was carried out over 12 weeks (i.e., was not unlimited as PCIT is typically conducted), thus some of the families may not have had sufficient therapy time before contact was terminated. This was not felt to be a significant issue given that recent unlimited-session PCIT studies have found that the average treatment duration is 13 weeks (Eyberg et al., 1995; Schuhmann et al., 1998). There was also the potential for bias with the use of a single therapist (who was also the primary investigator) for both treatments. Independent treatment integrity and quality checks, however, suggest that treatment was delivered to both groups satisfactorily. Independent assessment of child-parent interactions (DPICS-II) was conducted only as a single observation period at each assessment point because of logistical and financial constraints. The failure to detect differences in child deviant behavior after intervention may be attributable to the fact that in a new context children may not have behaved as they might have in familiar surroundings, resulting in atypical behavior at pretreatment assessment. Other studies have carried out such assessments on two separate occasions, with a 1-week interval between assessments to increase the validity of these observations. Given the more modest effects observed in the $\mathrm{ABB}$ condition, longer follow-up is essential to determine whether these gains can be sustained. Replication of the study with an increased sample size would also allow finer-tuned outcome analysis in terms of comorbid conditions and age. Future studies would also benefit from measuring the acceptability of treatment to investigate the possibility that one format was favored over the other by parents.

Studies reporting modifications of PCIT are still in their infancy. Eyberg (2000) has recently initiated a large-scale study to examine 
the use of regular booster sessions (maintenance sessions) plus treatment versus a treatment-only condition, and Paravicini, Urquiza, and Blacker (2000) have described modifications of PCIT for use with children between 1 and 3 years. The findings of the current study suggest that the use of didactic videotapes and phone consultations will play a significant role in allowing PCIT (and other programs) to be more readily accessible and cost-effective to families in need. It is envisaged that future studies will continue to investigate such modifications to identify how best to disseminate programs for families with behaviorally disturbed children.

\section{References}

Abidin, R. R. (1995). Parenting Stress Index-Professional manual (3rd ed.). Odessa, FL: Psychological Assessment Resources.

Achenbach, T. M. (1992). Manual for the Child Behavior Checklist/2-3 and 1992 Profile. Burlington: University of Vermont, Department of Psychiatry.

Achenbach, T. M., \& Rescorla, L. A. (2000). Manual for ASEBA Preschool Forms \& Profiles. Burlington: University of Vermont, Research Center for Children, Youth, \& Families.

American Psychiatric Association. (1994). Diagnostic and statistical manual of mental disorders (4th ed.). Washington, DC: Author.

Arnold, D. S., O'Leary, S. G., Wolff, L. S., \& Acker, M. M. (1993). The Parenting Scale: A measure of dysfunctional parenting in discipline situations. Psychological Assessment, 5, 137-144.

Arnold, E. H., O'Leary, S. G., \& Edwards, G. H. (1997). Father involvement and self-reported parenting of children with attention-deficit/hyperactivity disorder. Journal of Consulting and Clinical Psychology, 65, 337-342.

Auerbach, V., Nixon, R., Forrest, K., Gooley, S., \& Gemke, G. (1999). Group intervention program for oppositional, noncompliant and aggressive preschoolers. Clinical Psychologist, 3, 30-34.

Barkley, R. A., \& Edelbrock, C. (1987). Assessing situational variation in children's problem behaviors: The Home and School Situations Questionnaires. In R. J. Prinz (Ed.), Advances in behavioral assessment of children and families (Vol. 3, pp. 157-176). London: JAI Press.

Brestan, E. V., Eyberg, S. M., Boggs, S. R., \& Algina, J. (1997). Parentchild interaction therapy: Parent's perceptions of untreated siblings. Child and Family Behavior Therapy, 19(3), 13-28.

Campbell, S. B., Ewing, L. J., Breaux, A. M., \& Szumowski, E. K. (1986). Parent-referred problem three-year olds: Follow-up at school entry. Journal of Child Psychology and Psychiatry, 27, 473-488.

Campis, L. K., Lyman, R. D., \& Prentice-Dunn, S. (1986). The Parental Locus of Control Scale: Development and validation. Journal of Clinical Child Psychology, 15, 260-267.

Chambless, D. L., \& Hollon, S. D. (1998). Defining empirically supported therapies. Journal of Consulting and Clinical Psychology, 66, 7-18.

Coie, J. D., \& Koeppl, G. K. (1990). Adapting intervention to the problems of aggressive and disruptive rejected children. In S. R. Asher \& J. D. Coie (Eds.), Peer rejection in childhood (pp. 309-337). New York: Cambridge University Press.

Connell, S., Sanders, M. R., \& Markie-Dadds, C. (1997). Self-directed behavioral family intervention for parents of oppositional children in rural and remote areas. Behavior Modification, 21, 379-408.

Dumas, J. E. (1989). Treating antisocial behavior in children: Child and family approaches. Clinical Psychology Review, 9, 197-222.

Eisenstadt, T. H., Eyberg, S., McNeil, C. B., Newcomb, K., \& Funderburk, B. (1993). Parent-child interaction therapy with behavior problem children: Relative effectiveness of two stages and overall treatment outcome. Journal of Clinical Child Psychology, 22, 42-51.

Eyberg, S. M. (1988). Parent-child interaction therapy: Integration of traditional and behavioral concerns. Child and Family Behavior Therapy, 10(1), 33-46.
Eyberg, S. M. (1992). Assessing therapy outcome with preschool children: Progress and problems. Journal of Clinical Child Psychology, 21, 306311.

Eyberg, S. M. (2000, May). What is PCIT? Paper presented at the First Annual Parent-Child Interaction Therapy Conference, Sacramento, CA.

Eyberg, S. M., Bessmer, J., Newcomb, K., Edwards, D., \& Robinson, E. A. (1994). Dyadic parent-child interaction coding system-II: A manual. (Social and behavioral sciences documents, No. 2897). San Rafael, CA: Select Press.

Eyberg, S. M., Boggs, S. R., \& Algina, J. (1995). Parent-child interaction therapy: A psychosocial model for the treatment of young children with conduct problems and their families. Psychopharmacology Bulletin, 31, 83-91.

Eyberg, S. M., Edwards, D., Bessmer, J., \& Litwins, N. (1994). The workbook: A coder training manual for the dyadic parent-child interaction coding system -II (Social and behavioral sciences documents No. 2898). San Rafael, CA: Select Press.

Eyberg, S. M., \& Pincus, D. (1999). Eyberg Child Behavior Inventory and Sutter-Eyberg Student Behavior Inventory-Revised: Professional manual. Odessa, FL: Psychological Assessment Resources.

Foote, R., Eyberg, S., \& Schuhmann, E. (1998). Parent-child interaction approaches to the treatment of child behavior problems. In T. H. Ollendick \& R. J. Prinz (Eds.), Advances in clinical child psychology (Vol. 20, pp. 125-151). New York: Plenum Press.

Gibaud-Wallston, J., \& Wandersman, L. P. (1978, August-September) Development and utility of the Parenting Sense of Competence Scale. Paper presented at the 86th Annual Meeting of the American Psychological Association, Toronto, Ontario, Canada

Hanf, C. A. (1969, April). A two-stage program for modifying maternal controlling during mother-child $(M-C)$ interaction. Paper presented at the meeting of the Western Psychological Association, Vancouver, British Columbia, Canada.

Hembree-Kigin, T. L., \& McNeil, C. B. (1995). Parent-child interaction therapy. New York: Plenum Press.

Herschell, A. D., Calzada, E. J., Eyberg, S. M., \& McNeil, C. B. (2002). Parent-child interaction therapy: New directions in research. Cognitive and Behavioral Practice, 9, 9-15.

Jacobson, N. S., \& Truax, P. (1991). Clinical significance: A statistical approach to defining meaningful change in psychotherapy research. Journal of Consulting and Clinical Psychology, 59, 12-19.

Johnston, C., \& Mash, E. J. (1989). A measure of parenting satisfaction and efficacy. Journal of Clinical Child Psychology, 18, 167-175.

Kazdin, A. E. (1987a). Conduct disorders in childhood and adolescence. Thousand Oaks, CA: Sage.

Kazdin, A. E. (1987b). Treatment of antisocial behavior in children: Current status and future directions. Psychological Bulletin, 102, 187203.

Kazdin, A. E., \& Wassell, G. (1999). Barriers to treatment participation and therapeutic change among children referred for conduct disorder. Journal of Clinical Child Psychology, 28, 160-172.

Kazdin, A. E., \& Weisz, J. R. (1998). Identifying and developing empirically supported child and adolescent treatments. Journal of Consulting and Clinical Psychology, 66, 19-36.

Kendall, P. C. (Ed.). (1999). Clinical significance [Special section]. Journal of Consulting and Clinical Psychology, 67, 283-339.

Lavigne, J. V., Arend, R., Rosenbaum, D., Sinacore, J., Cicchetti, C., Binns, H. J., et al. (1994). Interrater reliability of the DSM-III-R with preschool children. Journal of Child Abnormal Psychology, 22, 679690.

Lavigne, V. V., \& Reisinger, J. J. (1984). Behavioral interventions with noncompliant preschoolers. In W. J. Burns \& J. V. Lavigne (Eds.), Progress in pediatric psychology (pp. 241-276). New York: Grune \& Stratton.

Lefcourt, H. M. (1991). Locus of control. In J. P. Robinson, P. R. Shaver, 
\& L. S. Wrightsman (Eds.), Measures of personality and social psychological attitudes (pp. 413-419). New York: Academic Press.

Matthey, S., \& Barnett, B. (1999). Normative data for an Australian clinical sample on the Home Situations Questionnaire-Modified Version (HSQ-M). Behaviour Change, 16, 207-218.

McMahon, R. J. (1994). Diagnosis, assessment, and treatment of externalizing problems in children: The role of longitudinal data. Journal of Consulting and Clinical Psychology, 62, 901-917.

McNeil, C. B., Capage, L. C., Bahl, A., \& Blanc, H. (1999). Importance of early intervention for disruptive behavior problems: Comparison of treatment and waitlist-control groups. Early Education and Development, 10, 445-454.

McNeil, C. B., Eyberg, S., Eisenstadt, T. H., Newcomb, K., \& Funderburk, B. (1991). Parent-child interaction therapy with behavior problem children: Generalization of treatment effects to the school setting. Journal of Clinical Child Psychology, 20, 140-151.

Miller, L. S. (1994). Primary prevention of conduct disorder. Psychiatric Quarterly, 65, 273-285.

Nixon, R. D. V., Sweeney, L., \& Touyz, S. W. (1999, July). Treatment of oppositional preschoolers: A comparison of standard and abbreviated treatments. Paper presented at the 22nd National Conference of the Australian Association for Cognitive and Behaviour Therapy, Fremantle, Australia.

Paravicini, S. F., Urquiza, A. J., \& Blacker, D. M. (2000, May). Parentchild attunement therapy: Development of a program for children one to three years old. Paper presented at the First Annual Parent-Child Interaction Therapy Conference, Sacramento, CA.

Patterson, G. R., Dishion, T. J., \& Chamberlain, P. (1993). Outcomes and methodological issues relating to treatment of antisocial children. In T. R. Giles (Ed.), Handbook of effective psychotherapy (pp. 43-88). New York: Plenum Press.

Reid, J. B. (1993). Prevention of conduct disorder before and after school entry: Relating interventions to developmental findings. Development and Psychopathology, 5, 243-262.

Rogers, J. L., Howard, K. I., \& Vessey, J. T. (1993). Using significance tests to evaluate equivalence between two experimental groups. Psychological Bulletin, 113, 553-565.

Sanders, M. R. (1996). New directions in behavioral family intervention with children. In T. H. Ollendick \& R. J. Prinz (Eds.), Advances in clinical child psychology (Vol. 18, pp. 283-330). New York: Plenum Press.

Schuhmann, E. M., Foote, R. C., Eyberg, S. M., Boggs, S. R., \& Algina, J. (1998). Efficacy of parent-child interaction therapy: Interim report of a randomized trial with short-term maintenance. Journal of Clinical Child Psychology, 27, 34-45.

Smith, A. M., \& O'Leary, S. G. (1995). Attributions and arousal as predictors of maternal discipline. Cognitive Therapy and Research, 19, $459-471$

Sutton, C. (1992). Training parents to manage difficult children: A comparison of methods. Behavioural Psychotherapy, 20, 115-139.

Webster-Stratton, C. (1984). Randomized trial of two parent-training programs for families with conduct-disordered children. Journal of Consulting and Clinical Psychology, 52, 666-678.

Webster-Stratton, C. (1991). Annotation: Strategies for helping families with conduct disordered children. Journal of Child Psychology and Psychiatry, 32, 1047-1062.

Webster-Stratton, C. (1993). Strategies for helping early school-aged children with oppositional defiant and conduct disorders: The importance of home-school partnerships. School Psychology Review, 22, 437-457.

Webster-Stratton, C., \& Hammond, M. (1997). Treating children with early-onset conduct problems: A comparison of child and parent training interventions. Journal of Consulting and Clinical Psychology, 65, 93109.

Webster-Stratton, C., Kolpacoff, M., \& Hollinsworth, T. (1988). Selfadministered videotape therapy for families with conduct-problem children: Comparison with two cost-effective treatments and a control group. Journal of Consulting and Clinical Psychology, 56, 558-566.

Weisz, J. R., Thurber, C. A., Sweeney, L., Proffitt, V. D., \& LeGagnoux, G. L. (1997). Brief treatment of mild-to-moderate child depression using primary and secondary control enhancement training. Journal of Consulting and Clinical Psychology, 65, 703-707.

Received January 9, 2001

Revision received March 6, 2002

Accepted March 11, 2002 